\title{
Love and Money by Parental Matchmaking: Evidence from Urban Couples in China
}

\author{
Fali Huang Ginger Zhe Jin Lixin Colin $\mathrm{Xu}^{*}$
}

Marriage formation is often modeled as a matching process where males and females meet randomly or via commercial agents (Weiss 1997). This approach omits a unique feature of marriage, that is, not only does a marriage tie the knot between two individuals; it also affects the welfare of their parents. Such externality has been important in history and remains so in many developing countries (Cheung 1972, Anderson 2003). Probably because of such externality, parents are often involved in matchmaking for their children. A natural question that has not been answered in the literature is: Is there any agency cost when one's own parents act as the matchmaking agent?

In this paper we show that parental matchmaking may distort children's spouse choice because parents are more willing to substitute love for money than individuals themselves. The rationale is that the joint income of married children can be shared among extended family members more easily than mutual attraction felt by the couple themselves, and as a result, the best spouse candidate in the parents' eye can differ from what is optimal to the individual, even though parents are altruistic and care dearly about their children's welfare.

We find supporting evidence for this prediction using a unique sample of urban couples in China in the early 1990s: The estimated effects of parental involvement are indeed negative on marital harmony but positive on joint couple incomes. An instrumental variable approach is used to address the endogenous self-selection issues of both individuals and parents.

This paper contributes to the literature by providing new insights on the impact of matchmaking means on marriage outcomes. Unlike the classical focus on the effects of sex ratio, divorce law or educational composition on marriage outcomes, we highlight the institutional 
details of how the match is accomplished in the first place. The trade-off between love and other marriage outcomes is also explored by Fernandez et al. (2005) but from a different perspective of sorting and income inequality; they do not discuss different matchmaking methods at all. In a related paper, Edlund and Lagerlof (2006) show that the shift from parental to individual consent in marriage allows the young couple instead of their parents to receive the bride price and thus facilitates economic growth. In comparison, our focus is not on who controls resources in a marriage, but on the agency cost of relying parents as matchmakers.

\section{Hypotheses and Empirical Implications}

Our main prediction can be formally generated from a theoretical model where the son chooses whether to search for a potential wife himself or to delegate his parents to conduct the search for him. The results also apply to a woman searching for husband; the man's case is used only to simplify the exposition, which also applies to the empirical part. We find that the effects of parental involvement in marriage search may differ across the two types of marriage outputs: It is negative for the emotional output but is positive for the economic or other household outputs preferred by parents. These distinct effects are driven by the fact that the attraction between two individuals is idiosyncratic to the couple and thus not easily shared or evaluated by others, while the economic and household outputs produced by the couple can be shared among other family members, and thus even altruistic parents have more incentives to care about the potential wife's earning capabilities than how attractive she appears to their son.

A related result from such theoretical analysis is that parental involvement in marital search is endogenous; it is more likely to happen when the son's human capital level is lower or his searching cost is higher, and when his parents benefit more from the household public good or are more competent in search. In other words, in a fixed marriage market, there are two 
sources of self-selection in the choice of search methods: one is the adverse selection of sons and the other is the positive selection of parents. So a young man with a lower human capital and more capable or more motivated parents is more likely to rely on his parents to search for wife. Without properly accounting for these two sources of endogeneity problem, the OLS estimate of the effect of parental involvement in matchmaking can be either higher or lower than the true effect, depending on which selection effect is dominant.

Our approach is to include as many as possible variables controlling for both individual and parental characteristics to mitigate the effects of the selection problems, and to use an instrumental variable that affects an individual's choice of search method but not the marital outcomes directly. Consider two identical marriage markets A and B that are mutually exclusive. Due to some exogenous shocks, there is an upward shift in parental searching cost in market A that affects all individuals to the same extent, which will induce individuals at the margin to change their search method from parental involvement to self-search, while their counterparts in market B, not affected by any shocks, would still adopt parental involvement; and so as a result, identical individuals make different choices. Comparing their differences in marital outputs will thus lead to the true effect of parental involvement. This implies that we need to compare individuals across mutually exclusive but still comparable marriage markets, which is possible in our unique data set of Chinese urban couples at early 1990s due to the huge size of China and its strict policies that severely reduced individual mobility across provinces.

\section{Data Description}

We use the Study of the Status of Contemporary Chinese Women (SSCCW), a data set collected jointly by the Population Institute of Chinese Academy of Social Science and the Population Council of United Nations in 1991, which used stratified random sampling to select households 
from seven areas, one municipality (Shanghai) and 6 provinces (Guangdong, Sichuan, Jilin, Shandong, Shanxi, and Ningxia), that scatter in the southeast, south, southwest, northeast, east, middle and north of China, respectively. As long-distance migration was uncommon in China by 1991, we treat each province as a separate marriage market. Moreover, the rigid Hukou system effectively blocked people from migrating between cities and countryside; economic structure and life styles also differ dramatically between urban and rural areas, which in many important ways affect both matchmaking methods and marriage outcomes. In this paper, we focus on the urban sample of 3900 couples, where monetary incomes are the main indicator of economic outputs for households, and there is more comparability across cities in different areas in terms of economic and social development; detailed analysis of rural areas is treated in a separate paper.

Parental Involvement. The question on matchmaking asks how a husband met his spouse initially. There are four categories in the raw data: introduced by parents or relatives, by friends, by themselves, and by other means. We define a dummy variable Parental Involvement equal to 1 if the husband has been matched by the introduction of parents or relatives and 0 otherwise. We do not distinguish parents from relatives mainly because relatives are an integrated part of the parents' social networks, which is probably also the underlying reason that such distinction is not considered in the survey and hence not available in the data. A perhaps more debatable decision is not differentiating couples initially introduced by friends from those who met by themselves. The reason is that these two groups are very similar: In both cases, it is the young couple themselves (not their parents) that conducted the search and bore the search cost; their similarity is indeed confirmed by examining the raw data and regression results.

Harmony Index. Marriage outcomes are categorized in the analysis by two types: love and money. The economic output is measured by the joint couple income reported in the survey; 
the emotional aspect of the marriage output, however, is difficult to accurately quantify. We propose that an indicator of harmony within a couple is a plausible proxy for the love dimension of marriage for Chinese couples in the sample. Based on the survey question "How do you usually reconcile with your spouse when you have conflicts?", we define a variable Harmony Index equal to 2 if the husband reports no conflicts, 1 if conflicts are usually solved by mutual compromise, and 0 if conflicts are solved by either unilateral compromise or third-party mediation by family members, relatives or friends. Since third-party involvement in conflict solution is a rare event in the data (only $3 \%$ reported so), we do not distinguish it from unilateral compromise. The implication is that "no conflicts" is the best outcome, while "mutual compromise" comes next in the ranking, which is arguably less costly or more effective than unilateral compromise and third-party mediation. In our view, this harmony index captures the essential meaning of a couple's match quality: Couples of better match quality are less likely to have conflicts and more capable of solving conflicts in an effective way. To be clear, we are aware of the possibility that in some isolated scenarios, unilateral compromise may be preferred or more effective, but as the routine mode of conflict resolution within the couple, mutual compromise, whether in substantial or symbolic ways, may indicate a more harmonious relationship. We have also tried treating the harmony index as ordinal or focusing on whether a couple has any conflict or not, and get similar estimation results. Alternative measures of the emotional output of marriage used in the literature, such as whether a couple ends up with divorce or subjective measures of marital satisfaction, are either inadequate or unavailable in the survey. As a matter of fact, the divorce rate in China in 1990 was 0.71 per 1000 couples, far below that of many countries (4.44 in the U.S. and 1.59 in Japan as of 1995, Zeng and Wu 2000). 
Tradition of Parental Involvement. To address the endogenous selection issue in the choice of matchmaking method, we use the Tradition of Parental Involvement in a marriage market as the instrumental variable for an individual's choice of parental involvement. Specifically, the tradition for everyone in a cohort $i$ is measured by the prevalence of parental involvement in an earlier cohort $i+2$ of the same gender in a province-urban unit, where individuals are divided into 8 age cohorts in each marriage market: the youngest cohort is of ages 18-25, followed by cohorts aged 26-30, 31-35, 36-40, 41-45, 46-50, 51-55, and finally 56 and above. For instance, the proportion of husbands of 41-45 years old using parental involvement will be the measure of tradition for all husbands of 31-35 years old in the same area. Since there is no corresponding measure of tradition for the two oldest cohorts in our sample, we have to drop them in our regression analysis. This tradition variable indeed differs across areas and cohorts in the data, and so identification comes from heterogeneity in parental matchmaking traditions across 7 marriage markets and 6 cohorts. We have tried other measures of parental involvement tradition and they yield similar regression results.

Due to either social learning, economy of scale, or the inclination to follow social customs (Cheung 1972), parents in an area with a stronger tradition of parental matchmaking would have a greater advantage in matchmaking and thus are more likely to engage in it for their children, which is independent of individual characteristics and hence teases out the endogenous selection problems. The exclusion criterion for a valid instrumental variable is also likely to hold: Except through parental involvement indirectly, the tradition should not have any direct effects on an individual couple's marital harmony and joint income, especially after controlling many individual, parental and provincial characteristics as well as cohort dummies. It is useful to note that this area-, cohort-, and gender-specific tradition is not affected by individual characteristics 
through sorting because Chinese had little freedom in changing residential locations at least up to 1991 due to strict enforcement of the Hukou system in particular and the planning economy in general. This is also evident in our data, where over 90 percent have never changed residence since age 12, and in most cases location change is due to parents' or spouse' change of job.

\section{Estimation Results}

The first panel in Table 1 shows that among urban couples, 16 percent are married with parental involvement; their harmony indices are significantly lower than those married by self-match while their joint couple incomes are significantly higher. These differences are consistent with our main hypothesis and also confirmed in regression results in Panel B, where the common control variables across these regressions include three categories: (1) Individual Characteristics: age, age squared, cohort dummies, years of schooling, health status, political party membership (whether the individual is a member of communist party, communist youth league, or democratic party), ethnic (Han, Huei, Korean, Manchurian), religion (Buddhist, Christian or Catholic, Muslim), type of the first job (state-owned sectors, individual farms or firms, collective firms, joint ventures or foreign firms), and whether current job is in a state-owned firm; (2) Parental Characteristics: years of schooling of both parents; and (3) Location Characteristics: whether the average education of parents is above the sample average, and whether the average couple income is higher than the sample average. The regressions do not control for the spouse's characteristics because they are endogenous to the matchmaking choice.

The estimated effects of parental involvement in matchmaking are negative for harmony but positive for income; the coefficients are smaller in scale and not significantly different from zero under OLS specification, possibly due to the two types of selection problems discussed above that exert opposite influences on the estimates, but they become statistically significant in 
the IV specification. The instrumental variable is highly significant in the first stage regressions, and the F-statistics are large enough to rule out the problem of weak instruments. Results for wives are similar and thus not shown. These results are robust to different sets of control variables, alternative methods to measure parental involvement tradition, defining conflict from the report of the couple instead of husband, and using ordinal measures of harmony index. Based on the IV results in Panel $\mathrm{B}$, the estimated effects of one standard deviation (SD) change in parental involvement for urban husbands are $-0.38 \mathrm{SD}$ of harmony and $0.53 \mathrm{SD}$ of log income.

A mechanism that may give rise to these results, as suggested by our theoretical analysis, is that matchmaking by parental involvement tends to overemphasize the earning capability of a potential spouse, which directly affects household public goods that can be shared among extended family members, than what is deemed optimal if one searches spouse on one's own. If this is true, then the spouse selection criteria should also differ systematically by matchmaking methods. There is indeed supporting evidence on this matter, which is shown in the last panel of Table 1. The variables listed are popular spouse selection criteria considered at the matchmaking stage, which are dummy variables equal to 1 if the specific trait is deemed as one of the two most important characteristics in selecting the marriage partner. Consistent with our story, the estimated effects of parental involvement under probit specification are negative on the character and temperament of potential spouses (affecting attractiveness within couple more) but positive on their family backgrounds and occupation (affecting earning potentials more), and all of these coefficients are highly significant, which are also robust to other specifications.

\section{Conclusions}

This paper examines a new aspect of marriage market, namely the matchmaking method, and investigates its effects on marital harmony and joint couple income using a unique sample of 
urban couples in China in the early 1990s. Specifically, we show that parents' involvement in the matchmaking process may distort children's spouse choice in that they tend to emphasize more on the potential spouse's earning ability than match quality or attraction between the couple. The rationale is that the joint income of married children can be shared among extended family members more easily than mutual attraction felt by the couple. Putting it differently, parents are often more willing to substitute love for money than the individuals themselves. Similar but more subtle distorting effects between love, market income, and parent-preferred goods or traits are also found among rural couples in China, which are reported in a separate paper.

Table 1: Parental Matchmaking and Marriage Outcomes for Urban Couples in China

\begin{tabular}{|c|c|c|c|}
\hline \multicolumn{4}{|c|}{ Panel A. Summary Statistics and Group Difference } \\
\hline & Parental Involvement & Harmony Index & $\underline{\text { Log (Couple Income) }}$ \\
\hline Mean (SD): & $0.16(0.36)$ & $1.02(0.73)$ & $9.92(0.76)$ \\
\hline Parental Involvement & & $0.98(0.73)$ & $9.95(0.71)$ \\
\hline Self Search & & $1.03(0.72)$ & $9.91(0.77)$ \\
\hline Difference & & $-0.05(0.02)^{* * *}$ & $0.04(0.02)^{*}$ \\
\hline
\end{tabular}

\begin{tabular}{lcccc}
\hline & \multicolumn{3}{c}{ Panel B. Regression Results for Husbands } \\
& \multicolumn{2}{c}{ Harmony Index } & \multicolumn{2}{c}{ Log (Couple Income) } \\
\cline { 2 - 5 } Parental Involvement & $-0.054(0.035)$ & $-0.769(0.382)^{* * *}$ & $0.037(0.028)$ & $1.113(0.362)^{* * *}$ \\
R-squared & 0.015 & - & 0.436 & 0.173 \\
Observations & 3,356 & 3,344 & 3,438 & 3,424 \\
First Stage Regression & & & & \\
Tradition & & $0.486(0.096)^{* * * *}$ & & $0.457(0.110)^{* * *}$ \\
F-statistic in the First Stage & 25.73 & & 23.36 \\
\hline
\end{tabular}

F-statistic in the First Stage

Panel C. Spouse Selection Criteria by Individuals (Probit)

\begin{tabular}{lcccc} 
& Character & Temperament & Family Background & Occupation \\
\cline { 2 - 5 } Parental Involvement & $-0.045(0.012)^{* * * *}$ & $-0.054(0.014) * * *$ & $0.032(0.008)^{* * *}$ & $0.028(0.010)^{* * *}$ \\
Adjusted R-squared & 0.011 & 0.018 & 0.007 & 0.006 \\
Observations & 7,703 & 7,703 & 7,703 & 7,703
\end{tabular}

Notes: Standard deviations are in the parentheses. ${ }^{* * *}$ Significantly different from zero at the 1 percent level; **at the 5 percent level; * at the 10 percent level. Control variables include an individual's age, age squared, years of schooling, health status, cohort dummies, political party membership variables (whether the individual is a communist party member, communist youth league, or a democratic party member), religion (Muslim, Christian or catholic, Buddhist), ethnic (Han, Huei, Korean, Manchurian), the types of first job (state-owned sectors, individual farms or firms, collective firms, joint ventures or foreign firms), whether current job is in state-owned firms, years of schooling of both parents, and location characteristics including whether the average education of parents is above the sample average and whether the average couple income is higher than the sample average. 


\section{References}

Anderson, Siwan. 2003. "Why Dowry Payments Declined with Modernization in Europe but Are Rising in India,” Journal of Political Economy 111(2), 269-310.

Cheung, Steven. 1972. “The Enforcement of Property Rights in Children, and the Marriage Contract," Economic Journal 82, 641-657.

Edlund, Lena, and Nippe Lagerlof. 2006. "Individual versus Parental Consent in Marriage: Implications for Intra-Household Resource Allocation and Growth," American Economic Review 96(2), 304-307.

Fernandez, Raquel, Guner Nezih, and John Knowles. 2005. "Love and Money: A Theoretical and Empirical Analysis of Household Sorting and Inequality," Quarterly Journal of Economics 120(1), 273-344.

Weiss, Yoram. 1997. "The Formation and Dissolution of Families: Why Marry? Who Marries Whom? And What Happens Upon Divorce?" Chapter 3, in M.R. Rosenzweig and O. Stark eds., Handbook of Population and Family Economics, Elsevier Science.

Zeng, Yi and Deqing Wu. 2000. "Regional Analysis of Divorce in China since 1980," Demography 37(2), 215-219.

*Fali Huang, School of Economics, Singapore Management University, 90 Stamford Road, Singapore 178903, flhuang@smu.edu.sg. Ginger Zhe Jin, University of Maryland \& NBER, Department of Economics, College Park, MD 20742, jin@econ.umd.edu. Lixin Colin Xu, World Bank, 1818 H Street, N.W., Washington, D.C., 20433, 1xu1@worldbank.org. The authors wish to thank Gary Becker, Yuyu Chen, William Evans, James Heckman, Thomas Lemieux, Yi Lu, Vijayendra Rao, Seth Sanders, Mary Shirley, Jeffrey Smith and participants at the Chicago-Remin Symposium on family and labor economics at the University of Chicago, University of Maryland workshop, the PAA conference, ESPE conference, and Asian Conference on Applied Micro-Economics/Econometrics at Tokyo for constructive comments and suggestions. Huang gratefully acknowledges the financial support of SMU Research Grant 10-C244SMU-002. The views expressed here do not implicate World Bank and the countries that it represents. 